\title{
HOW WE LEARN ABOUT THE BRAIN?
}

\author{
Ismail Sangkala \\ English Education Department \\ ismail@unismuh.ac.id
}

We're learning about the brain on something that has not happened. Jeri Janowsky said that what you learned two years ago that is information that has been long. Now the technology has been able to explain or illuminate the hidden mysteries of the brain. By studying this research revolution, we as a connoisseur or education practitioners find it helpful to know more about the systems and processes our brains work. We have understood that how many functions and mysterious things in our brain. This section has introduced the theory of revolutions and the instrument of the brain, so we no longer taboo will feel it when we see it and apply it. Changes in each decade are described structurally, thus providing a scientific reference for academics and practitioners of psychology.

This material also has opened a picture for the reader of the importance of technological advances to develop a particular field of science in psychology. So that we could conclude that the science and theory should always be developed with the times. Has been seen previously on scientific revolutions, growing every year or decade. It is a reflection of the ability of humans' raises and execute their research. As 
it is said that "There is no theory is wrong, but how do you see the theory useful for you" (Jeri JANOWSKY), this statement is intended to keep experimenting, do not be afraid to create new theories and methods for all of them back on their utilization.

As the end of this article, the authors conclude three things that must be done by an educator, among others:

1. Being "Literate Consumer" in the field of brain research, learning from research sources to conclude, Which can be trusted or not.

2. Action research requires not only teach theory. Begin around us from the smallest to produce products.

3. Disseminate information-This information to the general public. With the way through to several students to spread among both families and the environment. 